\title{
PADI GUNUNG PADA MASYARAKAT DAYAK, SEBUAH BUDAYA \\ BERCOCOK TANAM PENUTUR AUSTRONESIA \\ (MELALUI PENDEKATAN ETNOARKEOLOGI)
}

\section{The Dayak Mountaineous Rice, an Austronesian Cultures of Rice Cultivation (An Approach of Ethnoarchaeology)}

\author{
Ida Bagus Putu Prajna Yogi \\ Balai Arkeologi Kalimantan Selatan \\ Jl. Gotong Royong II, RT 06/ RW 03, Banjarbaru \\ Telp. (0511) 4781716 \\ Email: idabagus.prajna@kemdikbud.go.id
}

Naskah diterima: 27-12-2018; direvisi: 23-05-2018; disetujui: 28-05-2018

\begin{abstract}
Dayak is one large group of people occupying the island of Borneo which is the speakers. In public life Dayak rice plant is a plant that is very important. An interesting thing is, that there is rice in the Dayak community, especially people whose lives are still in the forest or inland are mountain rice. Not only that religious communities and indigenous arranged such that rice from the process of clearing up the rice consumed. A thing that is so strictly regulated the relationship between humans and rice (plants), and God. The problem that arises is how the sustainability of this traditional rice cultivation in Kalimantan and what caused the traditional culture of rice growing in these fields continues to this day on the Dayak community. This study uses ethnoarchaeology approach. The conclusion is almost all the Dayak people are not familiar with irrigation systems. Cultural sustainability of mountain rice is caused by several factors, namely: the state of geography, the potential for vast land, a culture that has been done for generations, and cost efficiency.
\end{abstract}

Keywords: austronesian, rice, agriculture, technology, borneo.

\begin{abstract}
Abstrak
Dayak merupakan salah satu kelompok besar masyarakat penghuni Pulau Kalimantan yang merupakan penutur bahasa Austronesia. Dalam kehidupan masyarakat Dayak, tanaman padi sangat dimuliakan dan seluruh masyarakat Dayak yang ada di Pulau Kalimantan. Suatu hal yang menarik yaitu, padi yang ada dalam masyarakat Dayak terutama masyarakat yang masih di dalam hutan atau pedalaman adalah padi gunung atau ladang. Religi masyarakat dan adat mengatur padi sedemikian rupa mulai dari proses membuka lahan hingga padi tersebut dikonsumsi. Permasalahan yang muncul adalah bagaimana keberlanjutan perladangan padi secara tradisional di Pulau Kalimantan dan apa yang menyebabkan budaya tradisonal penanaman padi secara perladangan ini terus berlangsung hingga kini. Penelitian ini menggunakan pendekatan etnoarkeologi. Kesimpulan yang diperoleh adalah hampir seluruh masyarakat Dayak tidak mengenal sistem irigasi dalam budaya. Kebersinambungan budaya padi gunung atau padi ladang ini disebabkan oleh beberapa faktor, yaitu: keadaan geografi, potensi lahan yang luas, budaya yang telah dilakukan secara turun temurun, dan kepraktisan.

Kata kunci: austronesia, padi, pertanian, teknologi, borneo.
\end{abstract}

\section{PENDAHULUAN}

Ada beberapa pendapat mengenai asalusul dan proses migrasi para penutur bahasa
Austronesia. Mengenai migrasi penutur bahasa Austronesia "Out of Taiwan" yang menyatakan tempat asal orang-orang Austronesia adalah 
Taiwan. Pendapat ini semula dikemukakan oleh Robert Blust berdasarkan kajian terhadap bahasa-bahasa dalam rumpun Austronesia. Ia juga mengadakan kajian terhadap proto-bahasa Austronesia yang berkaitan dengan flora, fauna, dan gejala alam lainnya. Kesimpulannya adalah bahwa tempat asal penutur bahasa Austronesia adalah Taiwan (Blust 1984-85, 1995). Pendapat Blust tersebut kemudian mendapat dukungan dari penelitian arkeologi Peter Bellwood, walaupun terdapat sedikit perbedaan dalam hal kronologi munculnya bahasa Austronesia, namun keduanya mempunyai pendapat yang sama tentang tahapan migrasi Austronesia, sebagai berikut. Migrasi petani prasejarah dari Cina ke Taiwan (5000-4000 SM), mereka belum berbahasa Austronesia. Setelah lama menetap barulah mengembangkan bahasa Austronesia. Migrasi dari Taiwan ke Filipina (sekitar 40003000 SM), mereka mengembangkan bahasa yang disebut Proto-Malayo-Polinesia. Migrasi dari Filipina ke arah selatan dan tenggara (3500 SM-sebelum 2000 SM), menuju ke Kalimantan, Sulawesi, dan Maluku Utara. Migrasi dari Maluku ke arah selatan dan timur (3000 SM atau 2000 SM), mencapai Nusa Tenggara dan pantai Utara Papua Barat. Pada periode tersebut orang Austronesia yang telah menghuni Kalimantan sebagian bermigrasi ke Jawa dan Sumatera. Migrasi dari Papua ke barat (2500 SM) dan Timur (2000 SM atau 1500 SM) menuju Oseania. Austronesia dari Jawa dan Sumatera kemudian ada yang bermigrasi ke Semenanjung Malaysia dan Vietnam pada sekitar 500 SM, pada periode yang hampir sama sebagian orang Austronesia dari Kalimantan ada pula yang berlayar hingga sejauh Madagaskar (Tanudirdjo \& Bagyo Prasetyo 2004, 82-84).

Bukti arkeologis, biologis, dan linguistik menunjukan bahwa kebudayaan bercocok tanam di Asia Tenggara dan Asia Pasifik dibawa oleh para penutur Austronesia (Diamond 2003, 597-603). Bukti-bukti kedatangan awal penutur Austronesia di Kalimantan saat ini sudah mulai tampak dari hasil beberapa penelitian. pada kehidupan para penutur
Austronesia padi merupakan tanaman yang sangat penting bagi kehidupan mereka. Setiap melakukan pembahasan mengenai penutur Austronesia, padi selalu mendapatkan peran penting untuk dibahas. Temuan padi pada masa neolitik tertua di Kalimantan hingga saat ini ialah di Gua Niah, Serawak, berdasarkan temuan tembikarnya diperkirakan lebih tua dari 4000 BP. Pertanggalan tersebut lebih tua dibandingkan teori "Out Of Taiwan" yang dinyatakan bahwa menyebarnya para penutur Austronesia di Pulau Kalimantan baru dimulai sekitar 3500 BP (Bulbeck 2008, 32).

Suku Dayak saat ini dianggap sebagai masyarakat asli yang tinggal sejak dahulu kala di Pulau Kalimantan. Suku Dayak di Pulau Kalimantan memiliki beragam sub suku dan memiliki sejarah yang berbeda. 'Dayak' adalah istilah umum yang pertama kali digunakan oleh para antropolog barat untuk menunjuk penduduk asli Kalimantan yang tidak beragama Islam (King 1993, dikutip Klinken 2006, 28). Orang Dayak umumnya tinggal di pedalaman. Orangorang yang disebut Dayak ini sesungguhnya terdiri dari beragam kelompok seperti Maanyan, Ngaju, Iban, Ot Danum, Meratus dan lain-lain. Meskipun kebudayaan mereka memiliki banyak kemiripan, masing-masing kelompok itu memiliki bahasa yang berbeda, dan umumnya tidak memahami satu sama lain. Menurut J. U. Lontaan, 1975 kelompok suku Dayak, terbagi dalam suku kurang lebih 405 sub. Masing-masing sub suku memiliki adat istiadat dan budaya yang hampir mirip terutama pada bahasa (Lontaan 1975, 23-24).

Saat ini masyarakat Dayak di pedalaman hanya sedikit yang hidup nomaden sebagai pemburu dan pengumpul makanan, tetapi sarana utama penghidupan sebagian besar adalah ladang berpindah (Sellato 1994). Kegiatan ladang berpindah mereka terutama melakukan penanaman padi gunung dan beberapa tanaman lainya (Schiller 2007, 71). Padi gunung merupakan padi gogo yang hidup tergantung pada musim dan dapat hidup di lahan tadah hujan. 
Migrasi orang Dayak dipengaruhi oleh faktor ekologi. Ada kompetisi memperebutkan hutan sekunder di antara masyarakat peladang dikarenakan membuka hutan primer lebih sulit dan memerlukan waktu yang lebih lama. Selain itu, wilayah yang sudah didiami merupakan wilayah yang kaya akan sumber daya sementara wilayah yang tidak atau belum diklaim oleh sekelompok masyarakat biasanya merupakan wilayah yang tidak subur. Oleh karena itu, sering kali mereka memutuskan untuk bermigrasi ke tempat baru guna melakukan ekspansi (perang) dalam rangka memperoleh hutan sekunder (Septriani 2015, 4-5).

Permasalahan yang muncul adalah bagaimana teknik pertanian padi gunung masyarakat Dayak dan keberlanjutan perladangan padi secara tradisional ini di Pulau Kalimantan serta apa yang menyebabkan budaya tradisonal penanaman padi secara perladangan ini terus berlangsung hingga saat ini pada masyarakat Dayak. Tujuan dari penelitian ini adalah untuk mengetahui teknik perladangan padi gunung yang dilakukan oleh masyarakat penutur bahasa Austronesia pada masa lalu. Selain itu juga untuk mengetahui faktor apa yang menyebabkan teknik perladangan padi gunung ini masih tetap berlangsung hingga saat ini.

\section{METODE}

Artikel ini merupakan hasil dari beberapa kegiatan penelitian arkeologi yang dilakukan di beberapa tempat di Pulau Kalimantan. Lokasi penelitian yang dipilih tersebut dianggap dapat mewakili budaya bercocok tanam padi gunung (ladang) di seluruh pulau Kalimantan oleh masyarakat Dayak. Lokasi tersebut adalah Hulu Sungai Pawan, Kalimantan Barat, Daerah Pegunungan Meratus, Kalimantan Bagian Selatan dan Tenggara, Daerah Kutai Barat dan Kutai Timur (gambar 1).

Data dalam penelitian ini adalah bersifat kualitatif, dimana pendekatan yang digunakan

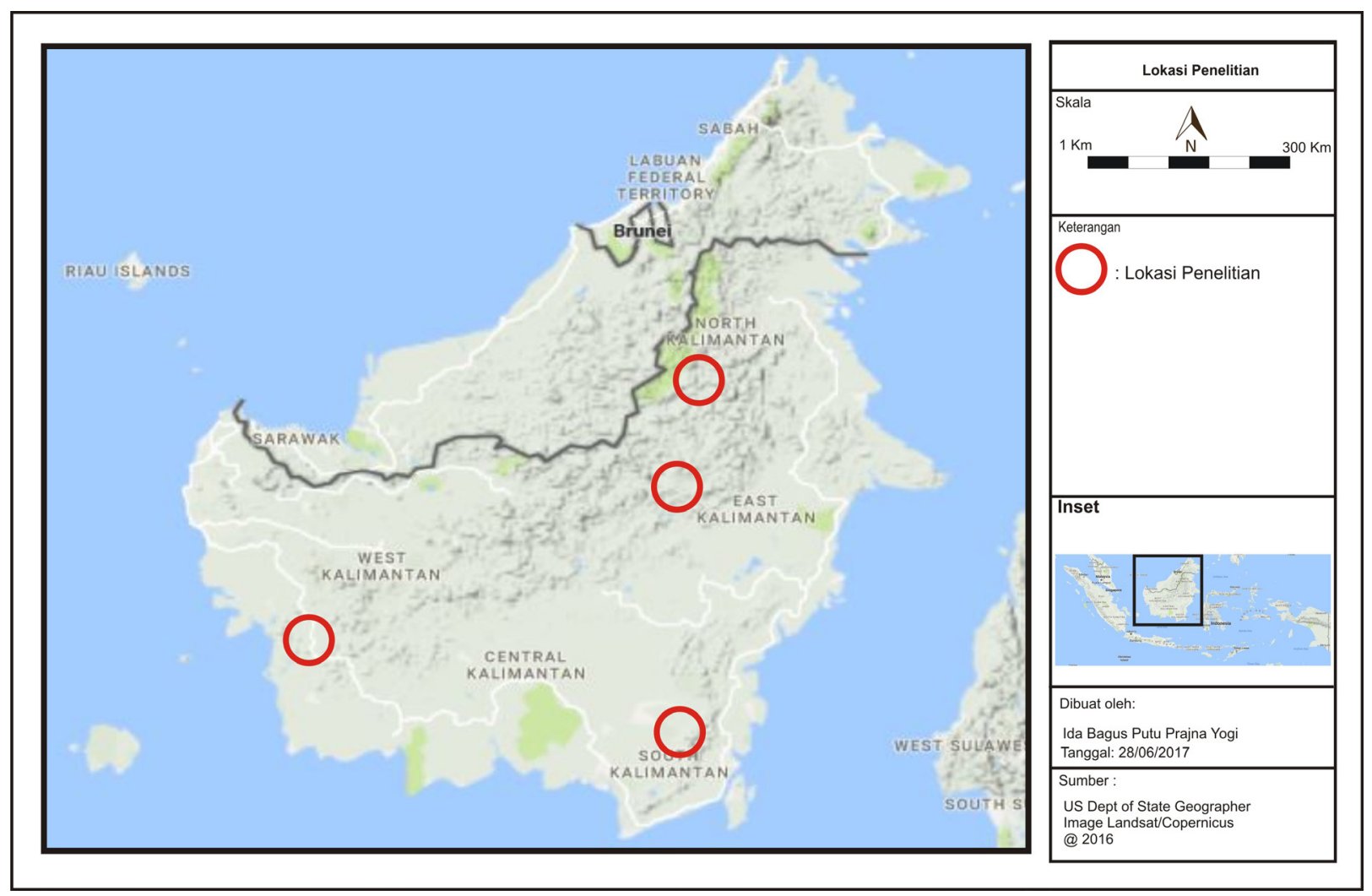

Gambar 1. Lokasi penelitian.

(Sumber: Digambar ulang oleh Ida Bagus Putu Prajna Yogi, 2016) 
adalah pendekatan etnoarkeologi. Oswalt (1974) menyatakan bahwa etnoarkeologi adalah penelitian yang dilakukan menggunakan perspektif arkeologi tentang budaya material, berdasarkan informasi lisan tentang artefak yang diperoleh dari orang yang berhubungan langsung dengan artefak tersebut atau keturunan langsung dari mereka (Ameer 1998, 18). Studi etnoarkeologi memiliki tujuan untuk memberikan gambaran rekonstruksi tentang masa lalu melalui tinggalan-tinggalan yang masih dijumpai dan dipergunakan hingga saat ini oleh sekelompok masyakarakat atau suku. Penggunaan data etnografi sebagai bahan analogi untuk mengungkap kembali tatacara kehidupan masa lampau biasanya mempunyai kedudukan sebagai interpretasi (Tanudirdjo 1987, 24).

Data diperoleh melalui observasi lapangan, survey, dan wawancara mendalam sebagai upaya untuk menggali data etnografi yang ada saat ini sehingga diharapkan dapat digunakan sebagai pendukung dalam proses rekontruksi mengenai teknologi pertanian padi gunung (ladang) di Pulau Kalimantan. Selain itu studi pustaka digunakan sebagai data sekunder dan pelengkap dalam tulisan ini.

\section{HASIL DAN PEMBAHASAN}

Sejak lama masyarakat Dayak sudah mengenal dan melakukan aktivitas berladang. Bukti pertanian padi di Kalimantan menunjukan pertanggalan 2000 SM. Pada awalnya mereka hanya membudidayakan jenis padi liar musiman. Kemungkinan besar pada masamasa awal membudidayakan padi mereka tidak menebang pohon karena terbatasnya peralatan yang dimiliki (Bellwood 2000, 356). Namun, penelitan terbaru yang dilakukan Bulbeck (2008) di Gua Niah Serawak diperoleh data pertanggalan mengenai domestikasi padi sudah berlangsung lebih tua dari 4000 BP (Hill 2010, 215-223).

Di daratan Asia berdasarkan analisis phytolit yang dilakukan dalam penelitian mengenai budidaya padi di Lembah Yangtze, menunjukan bahwa aktivitas pertanian padi yang baik di daerah tersebut telah berlangsung sejak 2350 BP dan meningkat pada 2100 BP. Keberlangsungan aktivitas pertanian di daerah tersebut mengalami pasang surut dalam perkembangannya karena naik turunnya permukaan air laut. Sehingga suatu waktu aktivitas pertanian tersebut akan berhenti manakala air laut naik ke wilayah pertanian (Itzstein-Davey 2007, 79-80).

\section{Teknologi Pertanian Padi Masyarakat Dayak}

Menurut Arkanudin (2001, 40), bahwa dalam setiap aktivitas berladang pada orang Dayak selalu didahului dengan mencari tanah. Dalam mencari tanah yang akan dijadikan sebagai lokasi ladang mereka tidak bertindak secara serampangan. Ukur (1994, 13), menjelaskan bahwa orang Dayak pada dasarnya tidak pernah berani merusak hutan secara intensional. Hutan, bumi, sungai, dan seluruh lingkungannya adalah bagian dari hidup.

Menurut Mubyarto (1991, 60-63), orang Dayak sebelum mengambil sesuatu dari alam, terutama apabila ingin membuka atau menggarap hutan yang masih perawan harus memenuhi beberapa persyaratan tertentu yaitu: pertama, memberitahukan maksud tersebut kepada kepala suku atau kepala adat; kedua, seorang atau beberapa orang ditugaskan mencari hutan yang cocok. Mereka akan tinggal atau berdiam di hutan-hutan untuk memperoleh petunjuk atau tanda, dengan memberikan persembahan. Usaha mendapatkan tanda ini dibarengi dengan memeriksa hutan dan tanah apakah cocok untuk berladang atau berkebun; ketiga, apabila sudah diperoleh secara pasti hutan mana yang sesuai, upacara pembukaan hutan itu segera dilakukan, sebagai tanda pengakuan bahwa hutan atau bumi itulah yang memberi kehidupan bagi mereka dan sebagai harapan agar hutan yang dibuka itu berkenan memberkati dan melindungi mereka.

Masyarakat di Kabupaten Kutai Barat mengenal beberapa tahapan, yaitu; (1) 
penjajagan diberi tanda (tumat tanaq), (2) menebas (So'an), (3) menebang (naveng ume), (4) membakar ladang (nutung ume), (5) membersihkan lahan sehabis dibakar (mohun ume), (6) persiapan menanam padi (nyilap iting), (7) menugal (nugu ume), (8) merumput (nawou ume), (9) panen padi (ngeluno ume), dan (10) menyimpan padi di lumbung (pesake pare nelapo loid) (Bagea, 2010: 43-51).

Sistem perladangan di Long Pujungan Kalimantan Timur sama dangan sistem perladangan lain di Kalimantan. Lahan diperoleh dengan membuka hutan, baik primer maupun sekunder. Long Pujungan, suatu lokasi ladang hanya dipergunakan sekali saja, atau maksimal dua musim tanam berturut-turut. Ladang yang telah dipakai dibiarkan menghutan kembali selama tiga sampai 25 tahun. Masyarakat di Long Pujungan mengenal klasifikasi hutan sebagai berikut: 1) Bekan: bekas ladang tahun lalu; 2) Jekau cengalem: bekas ladang ynag sudah dibiarkan menghutan selama 2 sampai 6 tahun; 3) Jekau lawan: bekas ladang yang sudah dibiarkan menghutan 7 sampai 15 tahun. Pohon yang tumbuh biasanya sudah mencapai diameter $15 \mathrm{~cm}$ sampai $50 \mathrm{~cm}$; 4) Jekau lempan: bekas ladang yang sudah sulit ditaksir berapa tahun sudah dibiarkan menghutan; ukuran pohonya biasanya berdiameter lebih dari $50 \mathrm{~cm}$; 5) $M b a$ ' atau Mpa': hutan rimba (Day 1999, 281-298).

Luas ladang yang dibuka oleh setiap keluarga berbeda-beda. Petani sejati membuka ladang seluas 2-4 ha, tergantung tersedianya tenaga kerja dalam kelompok senguyun, sedangkan para pegawai cenderung membuka ladang yang lebih kecil. Kadang-kadang juga suatu keluarga membuka ladang kedua, yang lebih kecil, dan ditanami padi sangkit (Ibid). Masyarakat Dayak di Kalimantan Timur juga mengenal istilah "Simpukng". Simpukng merupakan hutan sekunder yang digunakan untuk menanam tanaman-tanaman terpilih, seperti padi misalnya. Pemanfaatan hutan sekunder ini benar-benar diperhatikan oleh masyarakat adat karena lahan inilah yang menopang kehidupan mereka (Mulyoutami 2009, 2054-2061).

Sistem pertanian kering (perladangan) menunutut setiap keluarga di pedalaman Kalimantan untuk membuka hutan kira-kira dua hektar setiap tahunnya (Seavoy 1973, 219). Untuk membuka hutan yang masih perawan diperlukan tenaga ekstra, sebab pohon yang ditebang sangat rapat dan berukuran sangat besar. Pertumbuhan hutan yang kedua lebih disukai untuk dibuka, karena jauh lebih mudah untuk menebang dan jumlah tumbuhan tidak terlalu banyak. Suatu lahan setelah ditanam dan kemudian dipanen hasilnya, akan ditanami lagi pada periode delapan tahun kemudian. Periode delapan tahun tersebut, ukuran pohon yang tumbuh masih dapat dipotong dengan ukuran pisau semak besar (parang).

Pada proses penebangan, pohon pertama yang ditebang adalah pohon anakan, semak dan bambu yang membentuk tikar dasar sehingga mudah terbakar ketika mereka kering. Pohonpohon di tepi lahan ditebang ke dalam supaya api tidak menyebar ke vegetasi lain di luar lahan yang sudah ditentukan. Batasan terluar yang terdiri dari pohon-pohon besar dengan jarak lahan kosong yang bersih biasanya dibiarkan sebagai penjaga api. Daerah batasan terluar tersebut biasanya mereka sebut dengan sabuk pohon.

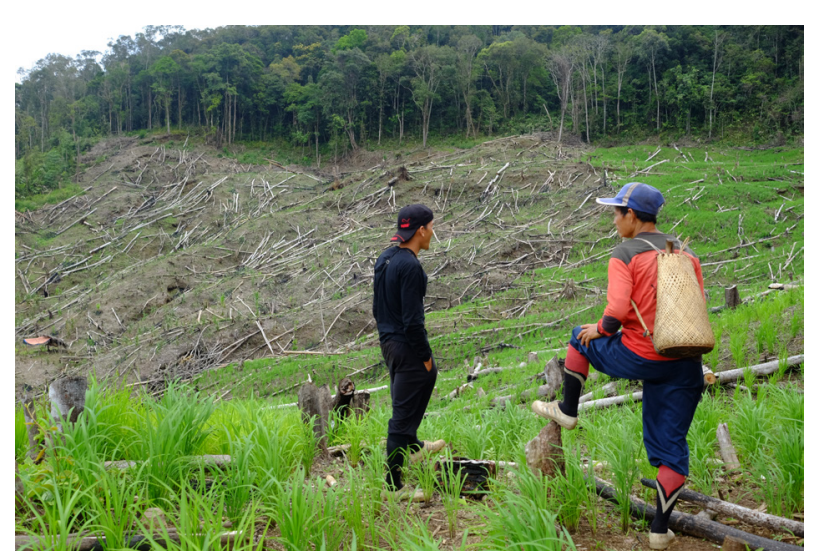

Gambar 2. Ladang gunung yang siap ditanami (Sumber: Dokumentasi pribadi) 
Setelah lahan bersih dan hangus terbakar oleh api, maka lahan yang luasnya kurang lebih dua hektar tersebut ditanami benih padi dalam satu hari oleh keluarga besar mereka yang jumlahnya dapat mencapai belasan bahkan puluhan orang. Biji padi tersebut dimasukan ke dalam lubang yang mereka buat dengan menancapkan sebuah kayu tajam yang mereka sebut dengan "tugal”, oleh karena itu kegiatan menancapkan ini mereka namai dengan kegiatan menugal. Lahan ditugal oleh lakilaki, sedangkan perempuan diberi kehormatan mengisikan benih ke lubang bekas tugal. Satu lubang diisi tiga-lima butir benih, agar tumbuhnya baik. Tidak hanya biji padi yang mereka tanam terkadang dalam proses menugal tersebut mereka juga memasukan biji mentimun atau jagung secara bersamaan. Biasanya mentimun dapat dipetik buahnya bersamaan ketika padi mulai mendekati masa panen atau sekitar enam bulan masa tanam. Sedangkan jagung dapat diambil hasilnya sebelum enam bulan.

Pembersihan gulma biasanya hanya dilakukan selama dua kali dalam satu masa tanam hingga padi dapat dipanen jika proses pembakaran lahan dapat berlangsung dengan baik. Namun, jika proses pembakaran tidak maksimal maka proses penyiangan dapat berlangsung hingga tiga atau empat kali. Tanaman padi harus dilindungi dari hewan pemakan rumput seperti rusa dan hewan lainnya. Biasanya bambu-bambu kecil dipasang di sekeliling ladang dengan diikat oleh rotan sehingga dapat menghalau hewan tersebut. Mendekati masa panen beberapa anggota keluarga silih berganti bergiliran menjaga ladang mereka dan tidur di pondok yang telah dibuat. Mereka mengusir burung disiang hari dengan menggunakan daun kelapa atau enau yang diikat menggunakan tali rotan dan ditarik agar bergerak, sedangakan di malam hari mereka berjalan menggunakan obor untuk mengusir babi hutan. Untuk mengusir hama, mereka akan membakar kulit kayu tambun raya. Asapnya akan mengusir wereng dan belalang. Daun pasak bumi juga biasa dipakai untuk mengusir hama dengan cara dibakar pula.

Dalam proses budidaya padi pada ladang berpindah ini, masyarakat Dayak tidak mengenal proses pemupukan. Nutrisi untuk pertumbuhan padi yang mereka tanam, mengandalkan kualitas tanah dan humus pada ladang hasil pembukaan hutan. Setelah proses menugal, mereka akan meninggalkan ladang padinya untuk beberapa saat, biasanya mereka kembali ke kampung. Mereka akan kembali lagi ke ladang hanya untuk menyiangi gulma. Sambil menunggu padi mereka siap untuk dipanen, masyarakat Dayak melakukan pekerjaan lainnya, seperti berburu, menangkap ikan di sungai, mencari kayu gaharu dan ada pula yang mengerjakan kerajinan rumahan.

Setelah padi menguning, kira-kira berumur enam bulan, padi tersebut akan dipanen. Pemanenan padi bisanya dilakukan secara bersama-sama oleh seluruh anggota keluarga dan beberapa warga kampung yang diminta untuk membantu proses panen tersebut. Padi gunung ini dipanen menggunakan ani-ani, yaitu semacam alat pemotong yang dijepit di tangan dan berfungsi hanya untuk memotong bagian atas tangkai padi.

Padi yang masih berbentuk gabah tersebut kemudian dikeringkan dengan dijemur di bawah matahari. Proses penjemuran, dapat dilakukan di ladang ataupun dibawa ke kampung. Padi yang basah tidak akan bertahan

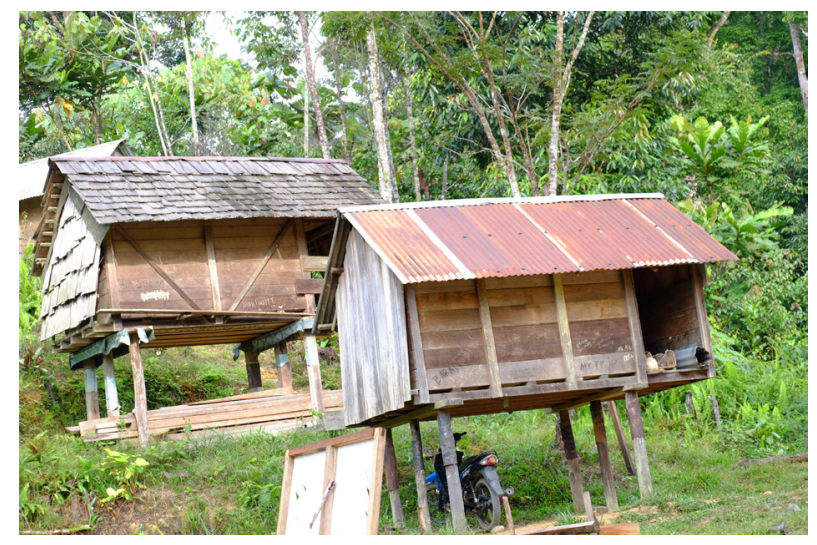

Gambar 3. Lumbung padi masyarakat Dayak Kenyah di Apau Kayan. (Sumber: Dokumentasi pribadi) 
lama dan mudah rusak. Panen yang berlimpah akan menambah jumlah stok padi mereka di lumbung keluarga atau di lumbung kampung. Di beberapa masyarakat Dayak padi tersebut tidak boleh diperjualbelikan, namun hanya untuk digunakan sebagai konsumsi pribadi atau untuk upacara adat. Namun, padi tersebut boleh saja diberikan kepada pihak lain.

\section{Padi dan Kemakmuran}

Perekonomian masyarakat Dayak tradisonal di Pulau Kalimantan bagian barat dan utara pada awal abadke dua puluh mengandalkan hasil pertanian dari padi gunung. Selain itu mereka juga memiiki mata pencaharian subsistensi dengan berburu, memancing, dan mengumpulkan hasil hutan, menyadap karet, dan budidaya lada. Masyarakat Dayak menanam padi dengan sistem perladangan berpindah melalui penebangan dan pembakaran vegetasi untuk tujuan penanaman tanaman, dengan abu memberikan nutrisi penting bagi tanaman mereka (Wadley 2007, 112).

Beberapa masyarakat Dayak juga ada yang menanam umbi-umbian atau mengambil umbi yang tumbuh liar di hutan. Namun, mereka tidak menganggap umbi-umbian tersebut sebagai makanan pokok. Masyarakat Dayak masih menganggap padi sebagai makanan pokok mereka (Boomgaard 2003, 590-596).

Ketersediaan cadangan padi dalam sebuah kelompok masyarakat Dayak dapat digunakan sebagai alat pengukur kemakmuran suatu komunitas (Helliwell 1995, 365-367). Dalam dua hektar lahan biasanya padi gunung ini dapat menghasilkan hingga $2000 \mathrm{Kg}$ gabah dalam sekali panen jika musim tanam tersebut berhasil.

Di sebagian besar suku-suku Dayak di Kalimantan penanaman padi ladang bertujuan untuk menghasilkan padi guna keperluan konsumsi subsistensi keluarga atau rumah tangga peladang itu sendiri. Pada masa lalu, produksi padi ladang ini digunakan untuk bahan makanan pada tahun ladang berikutnya produksi padi sebagai bahan makanan dapat dibagi lagi ke dalam tiga kegunaan, yaitu untuk bahan makanan sehari-hari, untuk keperluan penyelenggaraan ritual, dan untuk keperluan pertukaran dengan barang-barang kebutuhan hidup yang lain. Pertukaran ini sekarang sudah dilakuan di pasar guna untuk mendapatkan uang yang tunai. Kegunaan terpenting dari padi ladang adalah untuk keperluan benih padi, hasil panen biasanya tidak pernah digunakan untuk keperluan lain. Namun sampai saat ini masih ada Suku Dayak yang masyarakatnya pantang menjual padi.

Suku Dayak Meratus di Kalimantan Selatan adalah contoh produsen beras yang hanya menanam padi untuk dikonsumsi sendiri. Panen padi hanya sekali setahun, mereka berpantang menjual padi. Masyarakat di Desa Patikalaen, Kecamatan Hantakan, Hulu Sungai Tengah, menjelaskan mereka pernah mengalami kesulitan akibat menjual padi. Pengalaman kekurangan padi di saat kemarau panjang mendera, membuat mereka kembali ke nasihat leluhur yakni pantang menjual padi.

Pada masyarakat Dayak Meratus ada 26 varietas padi yang mereka tanam tanpa perlu membeli bibitnya. Padi yang ditanam itu ada banih ambulung, banih arai, banih banar, banih banyumas, banih banyumbang, banih briwit, banih buyung. Banih arai dan banih buyung, dianggap yang paling bagus berasnya. Banih arai dan banih buyung yang akan dijadikan benih di musim tanam berikutnya, disimpan di tempat khusus di lumbung. Ada pula banih harang, banih kalapa, banih kanjangah, banih kihung, banih kunyit, banih patiti, banih putih, banih sabai, banih sabuk, banih salak, banih saluang, banih santan lilin, banih siam unus, banih tampiko, banih uluran, dan banih wayan.

Mereka juga menanam padi ketan, yang akan dimasak sebagai lemang di acaraacara tradisi. Ada tiga varietas ketan, yaitu benih kariwaya, benih lakatan, dan benih samad. Padi ketan bahkan menjadi bahan sedekah. Warga yang hadir di acara mahanyari benih akan pulang membawa beras ketan dari keluarga yang mengadakan mahanyari ini. 
Mahanyari benih adalah upacara usai panen untuk mencicipi beras baru hasil panenan. Mahanyari berasal dari kata hanyar, berarti baru. Benih adalah sebutan padi masyarakat Banjar dan masyarakat Dayak Meratus. Setiap panen, mereka selalu menyisihkan gabah yang akan dijadikan benih musim tanam berikutnya.

\section{Padi dan Religi}

Kehidupan masyarakat Dayak sarat dengan ritual adat, mulai dari perladangan, kelahiran, pengobatan hingga kematian. Upacara yang berkaitan dengan perladangan merupakan upacara yang paling sering dilakukan dan paling meriah ( Hartatik 2017, 167-168). Dalam kegiatan bertani masyarakat Dayak memanfaatkan hutan memiliki sejumlah aturan yang harus dipatuhi, hal ini dimaksudkan untuk menjaga agar hutan yang merupakan bagian dari kehidupan mereka tetap terjaga kelestariannya. Dalam pengelolaan hutan pada dasarnya orang Dayak selalu berpangkal dari sistem religi. Hakekat yang terkandung di dalam sistem religi adalah menuntun dan meneladani masyarakat Dayak untuk senantiasa berperilaku serasi dengan dinamika alam semesta, sehingga terwujud keseimbangan hubungan antara manusia dengan alam lingkungan.

Menurut Bamba $(1996,14)$, masyarakat dayak memandang alam tidak sebagai asset atau kekayaan melainkan sebagai rumah bersama. Konsep rumah bersama ini terlihat dalam setiap upacara yang mendahului kegiatan yang berkaitan dengan memanfaatkan hutan, dimana selalu terdapat unsur permisi atau minta izin dari penghuni hutan yang akan digarap. Suara burung atau binatang tertentu menjadi sarana komunikasi antara manusia dengan penghuni alam.

Kegiatan berladang padi oleh masyarakat di daerah pegunungan Meratus bagian selatan yaitu masyarakat Dayak Bukit, Dayak Halong, Dayak Dea, dan Dayak Loksado disebut bahuma. Pada kegiatan bahuma sendiri terdapat beberapa ritual yang harus dilakukan agar segala sesuatunya dapat berjalan dengan baik. Menurut Radam (2001, 343), religi orang Bukit pada masa kini sebenarnya adalah religi huma (berladang). Hal ini didasarkan kenyataan bahwa sebagian besar tindakan religius dan simbolis berkomunikasi dengan sesuatu yang dipandang adikodrati dan menggenggam nasib berada dalam semua aktivitas berladang (bahuma). Bagi masyarakat Meratus, padi berkaitan dengan kesuburan dan kehidupan, karenanya pihak perempuanlah yang harus menanamnya dan mengawali pemanenan. Bagi mereka, bidadari juga berkaitan dengan kesuburan dan kehidupan.

Pada kehidupan Suku Dayak Bukit, kegiatan berupacara sangat menonjol menyertai keyakinan mereka. Upacara yang rutin dilaksanakan Suku Dayak Bukit umumnya dimaksudkan untuk memelihara keyakinan yang ada, sehingga antara keyakinan dan upacara merupakan dua unsur esensial dan saling melengkapi; keyakinan menggelorakan upacara dan upacara membenarkan keyakinan. Berbagai upacara yang diselenggarakan dalam konteks budaya/religi huma Suku Dayak Bukit ini seluruhnya terkait dengan kegiatan berladang. Kegiatan berladang sendiri terdiri dari 7 tahapan yaitu; (1) tahap mencari lahan garapan, (2) tahap membuka lahan, (3) tahap membersihkan lahan, (4) tahap menanan bibit, (5) tahap memelihara, (6) tahap memanen, hingga upacara dalam rangka (7) menyucikan hasil panen agar siap dikonsumsi.

Selain ritual berkaitan kegiatan berladang terdapat juga upacara adat lainnya yang tidak berkaitan langsung. Adapun upacara yang umum dilakukan menyangkut hal bertani padi ialah; (1) basambu, merupakan ritual masyarakat Dayak di sekitar pegunungan Meratus untuk menyembut padi yang sudah berbuah (bunting) untuk meminta pertolongan pada leluhur agar padi tumbuh baik dan dihindarkan dari gagal panen. Acara ini dilaksanakan di dalam balai 1-3 malam pada akhir bulan maret ke awal bulan april, (2) aruh bawanang (mahanyari), aruh bawanang (tandun/umbun) ini dilakukan dalam rangka menyembut panen benih (padi) dan baru 
bisa dilaksanakan setelah seluruh kelompok kepala keluarga telah selesai memanen padinya. Upacara aruh ini biasanya dilaksanakan pada bulan Juni selama 3-5 malam di balai adat. Puncak dari tradisi ritual bahuma adalah aruh ganal (aruh besar), yakni pesta adat berupa syukuran atau selamatan yang dilakukan di balai (rumah adat). Aruh ganal disebut juga bawanang benih halin atau upacara mahanyari benih beras. Artinya, melakukan acara selamatan karena terpenuhi hajat mendapat hasil padi yang baik selama bahuma dan tidak mendapat musibah. Aruh ganal (penutup) merupakan aruh terakhir dan paling besar, biasanya dilaksanakan sampai tujuh hari tujuh malam di dalam balai, upacara ini di katakan pesta panen. Setelah selesai mengatam benih (menuai padi) berat dan waktunya ditentukan oleh tatuha balai (pimpinan balai). Aruh ini biasanya dilaksanakan dalam kelender Masehi jatuh pada bulan September.

Di Hulu Sungai Mahakam dan Hulu Sungai Barito, masyarakat Dayak Banuaq mengenal upacara nalin taun, yaitu upacara yang dilakukan di awal musim tanam padi. Upacara ini harus dilakukan dengan harapan agar panen padi dapat berlimpah (Sillander 2006, 322-327). Sistem perladangan masyarakat Dayak Benuaq di beberapa desa di Kutai Barat dikenal dengan istilah Simpukng. Walaupun di dalam Simpukng terdapat jenis tanaman namun ada sebagian besar lahan digunakan sebagai ladang untuk menanam padi, sebab mereka sangat khawatir jika suatu saat akan menghadapi kemarau panjang, oleh karena itu mereka berusaha menyiapkan cadangan padi cukup banyak walaupun mereka tidak menjual padi tersebut (Mulyoutami 2009, 4-6).

Menurut Kiang (1994:33), ada beberapa jenis burung yang dipercayai menjadi rasi bagi orang Dayak ketika mereka akan membuka hutan untuk dijadikan sebagai ladang yaitu: (a) burung Keto; (b) burung Buria; (c) burung Jantek; (d) burung Jeje; (e) burung Bubut; (f) burung Bura; (g) burung Lang; (h) burung Tabulangking; (i) burung Cabik Kapan; dan (j) burung Cacap. Sedangkan jenis binatang yang menjadi pratanda rasi menurut kepercayaan masyarakat adalah: (a) Kokor (sejenis Tupai); Kunink (sejenis Jangkrik); (c) Ular; (d) Kijang, (e) Semut Sembada (Semut Hitam Besar); (f) Ilik-ilik (sejenis Belalang); (g) Ansit (sejenis Jangkrik) dan (h) Papo/Geragah. Disamping itu juga ada beberapa jenis burung yang bukan merupakan rasi, tapi apabila masuk ke rumah bisa menjadi rasi misalnya burung Hantu dan burung Imbuk.

Adapun ciri dan makna dari rasi tersebut dapat diungkapkan sebagai berikut. Burung Keto, badannya kecil bunyi suara besar, sama dengan namanya dan jarang terdengar. Menurut kepercayaan orang Dayak Kanayant bahwa: (a) burung Keto lah yang membawa padi dari tempat tinggal Tuhan (dalam istilah Kanayant disebut Jubata) ke dunia; (b) jika suara burung Keto bersuara tunggal dan hanya satu ekor yang bersuara, maka ladang yang ada boleh dikerjakan, dan jika suaranya banyak sekali maka ladang yang ada tidak boleh dikerjakan; Burung Cece, badannya kecil suaranya sama dengan namanya dan suara cukup besar. Menurut kepercayaan orang Dayak Kanayant suara burung Cece pertanda kurang baik. Burung ini dipercaya mempunyai hubungan dengan dewa yang sangat ditakuti (dewa tanah, istilah Kanayant disebut kamang). Jika suara burung ini terdengar dari samping, belakang, atau depan menandakan: (a) dalam perjalanan pulang akan mendapat kesulitan; (b) pada waktu mengerjakan ladang, ladang tidak akan berhasil. Kemudian bila suara burung ini terdengar pada malam hari menandakan: (a) mungkin ada diantara keluarga yang akan meninggal; (b) rumah atau lumbung padi akan terbakar; Adatn, yaitu ranting atau dahan kayu jatuh tanpa ada penyebabnya, hal ini dipercaya akan mendatangkan bencana.

Menurut kepercayaan masyarakat Dayak, bilamana dalam aktivitas berladang terutama dalam memilih lokasi yang akan digarap menjumpai berbagai rasi tersebut, maka perlu dilakukan upacara dengan mempersembahkan 
sesajen dengan maksud agar roh-roh halus yang memiliki kekuatan gaib tidak mengganggu kehidupan mereka baik secara individu ataupun kelompok. Berbagai kepercayaan sebagaimana yang digambarkan tersebut, menandakan bahwa orang Dayak memiliki persentuhan yang mendalam terhadap mitos, yakni suatu kejadian yang dipandang suci, atau peristiwa yang dialami langsung oleh para leluhur, meskipun waktu terjadinya peristiwa itu tidak dapat dipastikan secara historis, namun sejarah kejadian itu bagi orang Dayak berfungsi sebagai norma kehidupan. Pemikiran seperti itu melahirkan suatu persepsi mereka tentang kearifan pengelolaan sumber daya hutan (Widjono 1995, 34).

\section{KESIMPULAN}

Masyarakat Dayak yang masih hidup secara tradisonal sebagian besar melakukan aktivitas perladangan. Padi merupakan tanaman pokok dalam perladangan masyarakat dayak tersebut. Dalam beberapa penelitian yang dilakukan di beberapa wilayah di pulau Kalimantan diperoleh gambaran tentang sistem pertanian masyarakat Dayak terutama mengenai tanaman padi. Pola dan teknik bercocok tanamnya hampir serupa di seluruh Pulau Kalimantan.

Padi gunung merupakan salah satu jenis padi yang dapat ditanam di lahan kering yang tidak memerlukan banyak air dan sangat cocok ditanam di daerah tempat masyarakat Dayak pedalaman saat ini bermukim. Masyarakat Dayak tradisonal, saat ini bermukim di daerah pedalaman dan memanfatkan banyak tanah di lereng perbukitan untuk bertani. Teknologi perladangan padi gunung yang dilakukan antara sub suku Dayak yang satu dengan yang lainnya hampir sama. Mereka memiliki teknologi pertanian yang sangat sederhana namun efektif karena berusaha beradaptasi dengan lingkungan alam dimana mereka bermukim.

Keberlangsungan pertanian padi gunung di Kalimantan ini dapat terjaga oleh masyarakat
Dayak disebabkan oleh beberpa faktor, yaitu; (1) ketergantungan masyarakat Dayak terhadap kebutuhan karbohidrat yang bersumber dari makanan padi, (2) teknologi bercocok tanam padi gunung telah diturunkan secara turuntemurun oleh nenek moyang mereka di seluruh pulau Kalimantan, (3) ketersediaan lahan yang memungkinakan di pedalaman pulau Kalimantan, (4) Kepercayaan masyarakat Dayak dengan tanaman padi sangat erat dalam aturan religi mereka, dan hampir semua religi dan upacara mereka selalu ada hubungannya dengan pertanian dan tanaman padi, (5) hampir sebagian besar masyarakat Dayak di Kalimantan tidak mengenal sistem persawahan irigasi.

\section{Daftar Pustaka}

Ameer, Naseem and K.Thimma Reddy. 1998. Settlement Archaeology. New Delhi : Reliance Publishing House.

Arkanudin. 2001." Perubahan" Sosial Peladang Berpindah Dayak Ribun Parindu Sanggau Kalimantan Barat, Bandung: Tesis Program Magister Pascasarjana Universitas Padjadjaran.

Bagea, Ishak, 2010. Metafora Dalam Bidang Pertanian Padi Masyarakat Dayak Buket Kabupaten Barat Kalimantan Timur" Suatu Tinjauan Linguistik Antropologi”. Jurnal Humaniora. Yogyakarta: Fakultas Ilmu Budaya, Universitas Gadjah Mada. Hlm. 4351

Bamba, John, 1996. Pengelolaan Sumber Daya Alam: MenurutBudaya DayakDan Tantangan Yang Di Hadapi, Dalam Kalimantan Review, Nomor 15 Tahun V, Maret-April 1996, Pontianak. Hlm 12-18.

Bellwood, Peter. 2000. Prasejarah Kepulauan IndoMalaysia Edisi Revisi. Jakarta: PT. Gramedia Pustaka Utama.

Blust, Robert. 1976. "Austronesian" Culture History: Some Linguistic Inferences and Their Relations to the Archaeological Record. Source: World Archaeology, Vol. 8, No. 1, Archaeology and "Linguistic"(Jun.). Oxford: Taylor \& Francis, Ltd. Hlm. 19-43.

Blust, Robert, 1984. "The Austronesian Homeland: a linguistic perspective", Asian Perspective. 26. 1. Hlm. $45-68$. 
Boomgaard, Peter. 2003. In the Shadow of Rice: Roots and Tubers in Indonesian History, 1500-1950. Source: Agricultural History, Vol. 77, No. 4. : Agricultural History Society. Hlm. 582-610.

Bulbeck, David. 2008. An Integrated Perspective on the Austronesian Diaspora: The Switch from Cereal Agriculture to Maritime Foraging in the Colonisation of Island Southeast Asia. Source: Australian Archaeology, No. 67, More Unconsidered Trifles: Papers to Celebrate the Career of Sandra Bowdler (Dec.,).Canbera:Australian Archaeological Association. Hlm. 31-52.

Day, Christianita. 1999. Perubahan Sosial-Ekonomi Dan Dampaknya Terhadap Organisasi Pertanian di Long Pujungan dan Long Alango. Dalam Buku "Kebudayaan Dan Pelestarian Alam, Penelitian Interdisipliner di Pedalaman Kalimantan". Jakarta: WWF Indonesia.

Diamond, Jared and Peter Bellwood. 2003. Farmers and Their Languages: The First Expansions. Source: Science, New Series, Vol. 300, No. 5619 (Apr. 25). Pennsylvania : American Association for the Advancement of Science. Hlm. 597-603.

Hartatik, Jejak Budaya Dayak Meratus Dalam Perspektif Etnoreligi. Yogyakarta: Penerbit Ombak.

Helliwell, Christine. 1995. Autonomy as Natural Equality: Inequality in 'Egalitarian' Societie. Source: The Journal of the Royal Anthropological Institute, Vol. 1, No. 2 :Royal Anthropological Institute of Great Britain and Ireland. Hlm. 359-375.

Hill, R.D., 2010. The Cultivation of Perennial Rice, an Early Phase in Southeast Asian Agriculture? Journal of Historical Geography 36: Elsevier: Hlm. 215-223.

Itzstein-Davey,Freea, David Taylor, John Dodson, Pia Atahan, Hongbo Zheng. 2007. Wild and Domesticated forms of Rice (Oryza sp.) in Early Agriculture at Qingpu, lower Yangtze, China: Evidence From Phytoliths. Journal of Archaeological Science 34: Elsevier.

Kiang, Edy, 1994. Naik Dango Antara Suatu Kepercayaan Dan Upacara Adat, Dalam: Suara Almamater Nomor 1 Tahun XI, April
1994, Pontianak: Universitas Tanjungpura.

Klinken, Gerry van. 2006. "Colonizing Borneo: State Building and Ethnicity in Central Kalimantan. Indonesia No. 81.

Lontaan, J.U, 1975. Sejarah-Hukum Adat dan Adat Istiadat Kalimantan Barat. Pontianak : Pemda Tingkat I Kalbar.

Mubyarto, dkk. 1991. Kajian Sosial Ekonomi Desa-desa Perbatasan Di Kalimantan Timur, Yogyakarta: Aditya Media.

Mulyoutami, Elok, Ratna Rismawan, Laxman Joshi. 2009. Local knowledge and management of simpukng (forest gardens) among the Dayak people in East Kalimantan, Indonesia: Forest Ecology and Management: Elsevier.

Radam, Noerid Haloei. 2001. Religi Orang Bukit. Yogyakarta: Yayasan Semesta.

Ronald E. Seavoy. 1973. The Transition to Continuous Rice Cultivation in Kalimantan Source: Annals of the Association of American Geographers, Vol. 63, No. 2: Taylor $\&$ Francis, Ltd. on behalf of the Association of American Geographers. Hlm. 218-225.

Schiller, Anne. 2007. Activism and Identities in an East Kalimantan Dayak Organization. Source: The Journal of Asian Studies, Vol. 66, No. 1. Cambridge: Association for Asian Studies. pp. 63-95.

Sellato, Bernard. 1994. Nomads of the Borneo Rainforest: The Economics, Politics, and Ideology of Settling Down. Trans. Stephanie Morgan. Honolulu: University of Hawai'i Press.

Septriani. 2015. Stop Collective Migrating and Change of Live Dayak Society at Tumbang Karuei Village Central Kalimantan: Thesis Postgraduate program Of Anthropology. Jogjakarta: Gadjah Mada University.

Sillander, Kenneth. 2006. Local Integration and Coastal Connections in Interior Kalimantan: The Case of the Nalin Taun Ritual among the Bentian. Source: Journal of Southeast Asian Studies, Vol. 37, No. 2. Singapore: Cambridge University Press on behalf of Department of History, National University of Singapore.

Tanudirdjo, Daud Aris. 1987. Laporan Penelitian Penerapan Etnoarkeologi di Indonesia. Yogyakarta: Fakultas Sastra Universitas Gadjah Mada Yogyakarta. 
Tanudirdjo, Daud A. \& Bagyo Prasetyo, 2004. "Model "Out of Taiwan dalam Perspektif Arkeologi Indonesia", dalam Polemik tentang Masyarakat Austronesia: Fakta atau Fiksi? Prosiding Kongres Ilmu Pengetahuan VIII, Lembaga Ilmu Pengetahuan Indonesia bekerja sama dengan Direktorat Jendral Pendidikan Tinggi Departemen Pendidikan Nasional. Hlm. 77-101.

Ukur, Pridolin. 1994. Makna Religi Dari Alam Sekitar Dalam Kebudayaan Dayak, Dalam Paulus Florus (editor),Kebudayaan Dayak, Aktualisasi dan Transfortasi, Jakarta: LP3SIDRD dengan Gramedia Widiasarana Indonesia.
Wadley, Reed L. 2007. Slashed and Burned: War, Environment, and Resource Insecurity in West Borneo during the Late Nineteenth and Early Twentieth Centuries. Source: The Journal of the Royal Anthropological Institute, Vol. 13, No. 1: Royal Anthropological Institute of Great Britain and Ireland.

Widjono, Roedy Haryo. 1995. Simpukng Munan Dayak Benuaq, Suatu Kearifan Tradisional Pengelolaan Sumber Daya Hutan, Pontianak: Dalam Kalimantan Review, Nomor 13 Tahun IV, Oktober- Desember. 